\title{
Malaria in Brazil: an overview
}

\author{
Joseli Oliveira-Ferreira',2,7, Marcus VG Lacerda³, Patrícia Brasil2,4, José LB Ladislau5, Pedro L Tauil6 and \\ Cláudio Tadeu Daniel-Ribeiro*1,2
}

\begin{abstract}
Malaria is still a major public health problem in Brazil, with approximately 306000 registered cases in 2009, but it is estimated that in the early 1940s, around six million cases of malaria occurred each year. As a result of the fight against the disease, the number of malaria cases decreased over the years and the smallest numbers of cases to-date were recorded in the 1960s. From the mid-1960s onwards, Brazil underwent a rapid and disorganized settlement process in the Amazon and this migratory movement led to a progressive increase in the number of reported cases. Although the main mosquito vector (Anopheles darlingi) is present in about $80 \%$ of the country, currently the incidence of malaria in Brazil is almost exclusively ( $99,8 \%$ of the cases) restricted to the region of the Amazon Basin, where a number of combined factors favors disease transmission and impair the use of standard control procedures. Plasmodium vivax accounts for $83,7 \%$ of registered cases, while Plasmodium falciparum is responsible for $16,3 \%$ and Plasmodium malariae is seldom observed. Although vivax malaria is thought to cause little mortality, compared to falciparum malaria, it accounts for much of the morbidity and for huge burdens on the prosperity of endemic communities. However, in the last few years a pattern of unusual clinical complications with fatal cases associated with $P$. vivax have been reported in Brazil and this is a matter of concern for Brazilian malariologists. In addition, the emergence of $P$. vivax strains resistant to chloroquine in some reports needs to be further investigated. In contrast, asymptomatic infection by P. falciparum and P. vivax has been detected in epidemiological studies in the states of Rondonia and Amazonas, indicating probably a pattern of clinical immunity in both autochthonous and migrant populations. Seropidemiological studies investigating the type of immune responses elicited in naturally-exposed populations to several malaria vaccine candidates in Brazilian populations have also been providing important information on whether immune responses specific to these antigens are generated in natural infections and their immunogenic potential as vaccine candidates. The present difficulties in reducing economic and social risk factors that determine the incidence of malaria in the Amazon Region render impracticable its elimination in the region. As a result, a malaria-integrated control effort - as a joint action on the part of the government and the population - directed towards the elimination or reduction of the risks of death or illness, is the direction adopted by the Brazilian government in the fight against the disease.
\end{abstract}

\section{Background}

During the late 1930s, the Northeast Region of Brazil was invaded by Anopheles gambiae and a severe malaria outbreak, with a $13 \%$ fatality rate in a largely immune-naïve population, astonished Brazilian malariologists and health authorities. Because of the shipping traffic between Brazil and Senegal at that time, it was assumed that the invader came from this African region, probably in French warships travelling in 70 hours from Dakar to Natal to conduct meteorological studies preparatory of

\footnotetext{
* Correspondence: ribeiro@ioc.fiocruz.br

${ }^{1}$ Laboratório de Pesquisa em Malária, Instituto Oswaldo Cruz, Fiocruz, Pavilhão Leônidas Deane - $5^{\circ}$ andar, Av. Brasil 4365, Manguinhos, Rio de Janeiro, RJ - CEP 21.045-900, RJ - Brazil

Full list of author information is available at the end of the article
}

the transatlantic flights to be done in the future commercial companies [1]. Organized efforts to eliminate this very efficient malaria vector succeeded in the first years of the 1940s. The episode is considered to be one of the most important and successful Brazilian public health control campaigns.

It is estimated that in the early 1940 s, malaria was a nationwide problem with around six million people, approximately $20 \%$ of the national population, infected each year [2]. However, during the late 1950s, a national and successful campaign, following the eradication aims dictated by WHO, gained strength in the country, decreasing malaria to its lowest level by 1960 , when only 36,9 thousand cases were registered [3]. Although the eradication programme of the Ministry of Health in Bra- 
zil - based on DDT spraying on the walls inside the houses and the use of chloroquine to treat febrile cases succeeded in freeing the majority of the country from malaria transmission by the late 1960s/beginning of the 1970s, it was, however, unable to contain the rapid spread of the disease in the Amazon Basin, where malaria still remains a serious health problem [4] (Figure 1).

From the mid-1960's onwards, Brazil underwent a rapid and disorganized settlement process in the Amazon, which witnessed a huge transformation. Colonization programmes, sponsored by the government, resulted in massive and uncontrolled migration and brought a new reality for which the area was not prepared. This migratory movement led to a progressive increase in the number of reported cases in the country that rose from 52000 in 1970 to 578000 in 1989 [3,5-7]. In 1992, the WHO sponsored a meeting on malaria control at Amsterdam (Netherlands), pushing Ministries of Health of countries where malaria was still endemic to adopt integrated malaria control measures focusing the decrease of malaria morbidity and fatality rather than its eradication [8].

The Brazilian National Programme for Malaria Control (Plano Nacional de Controle da Malária, PNCM), which had so far been based on DDT spraying in the intra- domicile of all houses of the endemic region (goal never achieved) and the diagnosis and treatment of present and recent febrile cases, reoriented its actions focusing them on early diagnosis and adequate treatment of cases. The policy of increasing the number of health posts able to perform these tasks started at that time and resulted, for the first time, in a decrease of the proportion of falciparum malaria cases (Figure 1). The highest figures were recorded in 1999 (637,470 cases), when the government decided to implement a plan to intensify the actions of the PIACM (Plano de Intensificação das Ações de Controle da Malária). The new plan had the main goals of reducing malaria incidence, morbidity (including the severe forms of the disease) and fatality; to eliminate malaria transmission in urban areas of the capitals of the Amazon States and to maintain the interruption of the disease transmission in places where this has been achieved. The Brazilian authorities also followed the recommendation of focusing the control strategies in the individuals rather than in the environment [9]. For this, the Secretary of Health Surveillance (SVS) of the Ministry of Health targeted an important expansion of the network of diagnosis/treatment stations in the Amazon. The figures were 1182 diagnostic laboratories, 2,656 malaria control agents and around $2,4 \times 10^{6}$ blood examinations

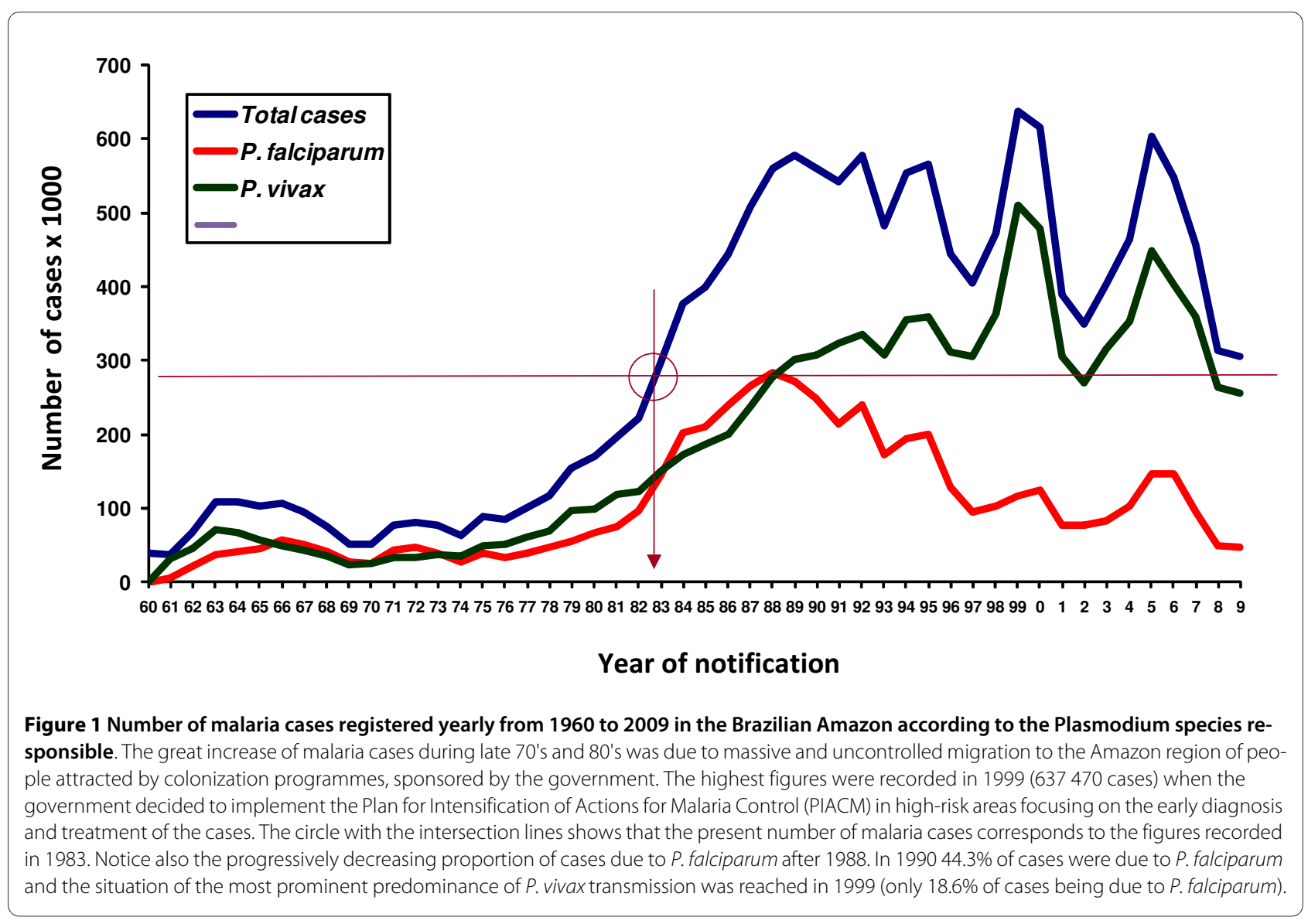


in 1999 as compared to the 3,492 diagnostic laboratories; 48,849 malaria control agents and around $2.8 \times 10^{6}$ blood examinations recorded in 2009 [10]. Apparently, the strategy of active case detection in some highly endemic areas, such as those in which Yanomami Indians were living, led to a sustained control of the disease [11]. However, the impact of this strategy by itself cannot be analyzed properly, because other interventions were applied at the same time as part of the PIACM, corroborating the idea that isolated interventions are not enough for the control [10].

However, a recrudescence of malaria transmission occurred in some localities of the Amazon and the incidence rose again from 2003 to 2005, bringing the figures to a situation almost comparable to that registered in 1999. The analysis of the reasons for this increase points to a multifactorial genesis of the phenomenon. This would involve climatic changes and migratory movements due to a disorderly occupation of the outskirts of large cities in the region as a result of agrarian reform projects and the consequent deforestation for logging, cattle ranching, agriculture, as well as for unofficial settlements. Poor performance in the implementation and administration of the actions prescribed by PNCM at the level of municipalities also contributed to increased transmission. Another contributor is the increase of the mosquito vector population as a result of an inadequate management of the environment. One example is the abandoned tanks used for fish-farming in the backyards of homes or on the outskirts of several towns in the Amazon region, as in Manaus, where they were common. To meet the new dynamics of transmission, the Ministry of Health initiated wide-ranging multi-sector mobilization of forces, mainly the health managers in states and municipalities in the Amazon region, to coordinate population movements and to prioritize surveillance, prevention and control of malaria on their agendas. The effects of this joint effort are reflected in a substantial reduction of cases from 2006 onwards. The number of cases fell thereafter to 456000 in 2007. The last available data show that, in 2008, an additional $31 \%$ reduction in the number of cases brought the figures $(314,420$ cases) to a situation comparable to that of 1983 (Figure 1). The Amazonian Annual Parasitological Index (API, number of cases/ thousand inhabitants) fell also from 31.9 in 1999 to 12.8 in 2008 [10]. In order to take advantage of this kind of results and information to improve and consolidate the malaria control actions, it is necessary to try to analyze and understand results that indicate success, as is done when facing failures of the control measures and worsening of the malaria situation. The Coordination of the National Control Programme considers that the strengthening of the local management capabilities, through the continued expansion of the diagnosis and treatment net- work, may account for the sustained reduction of cases from 2006 onwards. This produced a decrease in the rates of disease severity as well as the reduction of the numbers of municipalities at (high, medium and low) risk in the Amazon (Figure 2). According to the PNCM, the absence of such approaches may explain the concentration of cases in some counties, where management has not prioritized the control of malaria, or other conditioning factors.

It is also important to point out that, although Anopheles darlingi, the main mosquito vector, is present in about $80 \%$ of the country, the incidence of malaria in Brazil is almost exclusively ( $99.8 \%$ of the total number of cases) restricted to the Amazon Region, where a number of combined factors favor disease transmission and impair the use of standard control procedures (Figure 2)[3]. The number of cases in the nine States of the Brazilian Amazon has fluctuated over the years, increasing in some states where new settlements projects and gold mining activities are implemented. In addition, the transmission inside the region is not regularly distributed, since 57 (7.1\%) out of the 807 municipalities in the Amazon states account for $80 \%$ of the total registered malaria cases and three of these accounts for $18 \%$ of the Amazonian cases [10]. In addition, and unfortunately, the disease seems to be concentrated not only in localities, but also in some groups of individuals. Although the overall incidence of malaria is decreasing, an augmented proportion of the disease in women $(34,9 \%$ in 2003 to $38.6 \%$ in 2008) and children below 10 years of age (22,0\% in 2003 to $25,2 \%$ in 2008) has been recorded in the last years [10]. The reasons remain to be determined but environmental factors, such as proximity of houses to mosquito-breeding places, could be involved. A follow-up of a cohort of around 6,400 women at the Coari Municipality (Amazonas - Brazil) in 2001 and 2002 has shown that only $0.1 \%$ of parasitologically-negative women and $92 \%$ of the positive ones reported at least one past episode of malaria[12]. The economical development of the new borders in the Northern Brazil had a great impact and could explain the maintenance of the disease in cities like Manaus, a city of two-million inhabitants, with a tax-free status, which attracts thousands of workers from several parts of the country and abroad [13].

Any decision-making process depends on obtaining robust data on the parameters to be monitored. For this, it is necessary to implement an epidemiological surveillance system and to permanently strengthen and improve local structures to generate and record standardized information that can guide the decisions, both at a local and national level. One positive aspect of the PNCM is the way the management of epidemiological information and the consolidation of routine work are conducted. Its information system (SIVEP-Malaria) is now highly devel- 


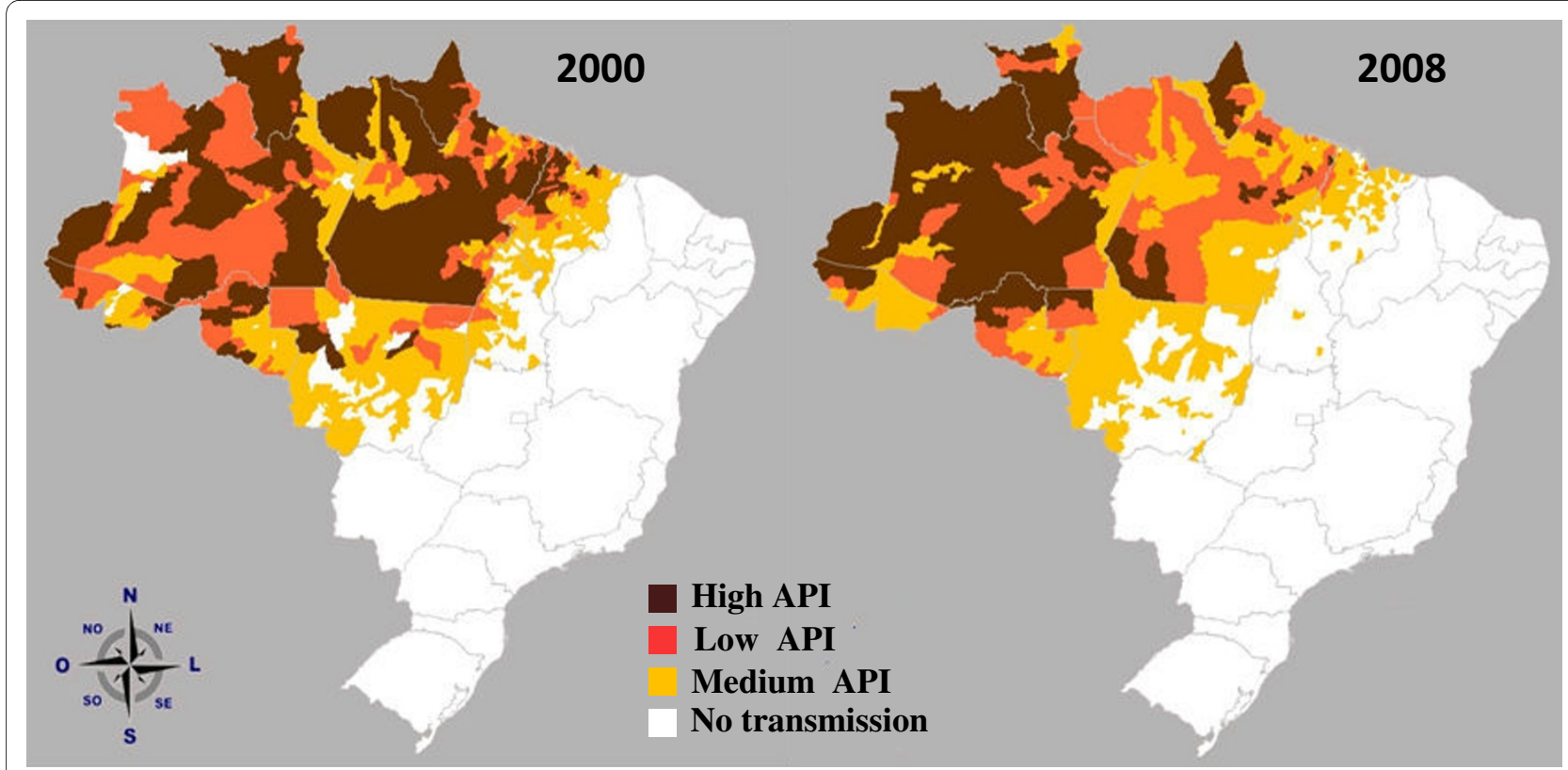

Figure 2 Areas of malaria transmission in Brazil according to the Annual Parasitary Index (API) in the years of 2000 and 2008. The Amazonian Annual Parasite Index (API, number of cases/thousand inhabitants) indicates success and failures of the control measures in some counties. Low API: < 10 cases; medium API: 10 to 49.9 cases; high API: > 50 cases. The distribution of transmission is not regular since 57 (7.1\%) out of the 807 municipalities in the Amazon states concentrate $80 \%$ of the total registered malaria cases and only three ( $0.4 \%$ ) of them accounts for $18 \%$ of the Amazonian cases.

oped and operates with a high coverage. All cases of malaria are included individually in a national database, with inputs from a network at the local level. The information recorded in the system is sent rapidly, via the web, to the regional levels and to the headquarters of the PNCM in Brasília. Automated reports are available online permanently, with input of approximately $42 \%$ of cases in eight days and $82 \%$ of cases in less than 30 days after the end of the corresponding month. Reports produced after 60 days of the period closure may cover more than $95 \%$ of cases. The SIVEP-Malaria database contains variables that allow the evaluation and selection of operational and epidemiological indicators, for which there are already pre-established routine analysis by the PNCM, and that are useful for monitoring and evaluating the situation. The system also allows monitoring of the scattering parameters of transmission in each city, which is useful to evaluate the degree of coverage of the diagnosis, treatment and use of insecticide-treated bed nets. Furthermore, the diagnosis offer versus the demand of cases can also be analyzed, in order to guide and adjust the diagnosis network. SIVEP provides also data related to the dispensing of drugs and the proportion of treatment failures among the diagnosed cases. The simplicity of the form guarantees a good quality of data and it is estimated that the system has a good sensitivity, since all the medication to treat malaria is distributed free by the Ministry of Health, through the reporting of cases. Nevertheless, the localized analysis of the system peculiarities in each municipality makes it possible to identify a heterogeneity of the general characteristics.

A project, recently submitted by the Brazilian Government (PNCM-Ministry of Health) and approved by the Global Fund, focuses the investment in epidemiological intelligence in strategic localities in the Brazilian Amazon and has the potential to change the history of malaria in Brazil. The goal of the project is to support and improve the capacity of local health services in order to enhance the understanding of the dynamics of the disease transmission and to conduct, with greater efficiency, the management of the intervention measures of the project and the control actions of the regular programme. The project aims to decrease morbidity and mortality in the Amazon region and the main expected result in the five-year project is a $50 \%$ reduction in the number of malaria cases in the 47 municipalities of the Amazon region, which had accounted for $70 \%$ of malaria cases in Brazil in 2007. The methodology is based on the strengthening of two recognized intervention measures: a) ensure early diagnosis and the administration of a timely treatment with effective drugs, amplifying the diagnosis network and improving the drug management, and b) quickly achieve high coverage of prevention with long-term insecticidetreated bed nets. The project is committed to concentrate in epidemiological intelligence and efficient management at the local level. This would be based on the establish- 
ment of a routine analysis for decision-making in close coordination with operating and management systems at all government levels (states and municipalities). This would also promote community organization and mobilization to facilitate participation in specific malaria control actions and improve acceptance of control measures by the communities.

In addition, we must emphasize the Brazilian capabilities of large-scale manufacturing of antimalarials. For instance, the association of artesunate/mefloquine produced by Farmanguinhos (Fiocruz) after a joint action of the Brazilian Ministry of Health and the Drugs for Neglected Diseases iniative (DNDi), is presented in dosages for adults and children, therefore facilitating drug intake and increasing adhesion to treatment. Currently, the State of Acre, in the Amazon, and all the States of the Extra-Amazonian Region successfully use the drug.

It is important to point out that the use of tools, such as artemisinin-based combination therapy, impregnated bed nets and rapid diagnostic tests, have not yet been evaluated in an integrated manner in a horizontal health system, such as the one offered in the Brazilian Amazon. This may indicate that the elimination of the disease in the country can be effectively achieved in the future. On the other hand, the analysis of available data, when the figures of malaria in Brazil achieve the situation of residual transmission in the future, may indicate the need of readapting the PNCM policy in view of the elimination of the disease in the Amazon Region and in the whole country.

Although the PNCM has succeeded in reducing drastically deaths, severe cases, hospitalizations and the national incidence of the disease, it seems important to consider its vulnerability, as the programme is based fundamentally on the diagnosis and treatment. In view of the potential emergence of $P$. falciparum resistance to artemisinin-based combination therapy and the absence of alternatives drugs, research programmes to identify new drugs that may replace the present ones are extremely important and urgently needed.

\section{The changing pattern of P. falciparum and P. vivax transmission}

In Brazil, malaria is caused by three species of Plasmodium: $P$. vivax (that accounts for $83,7 \%$ of the registered cases), $P$. falciparum (causing 16,3\% of the cases) and $P$. malariae (a small proportion of cases). No autochthonous transmission of $P$. ovale and P. knowlesi occurs [10]. Leônidas de Mello Deane, one of the most important Brazilian and world malariologists, used to say that the Superintendência de Campanhas (SUCAM, the national organization in charge of malaria control in Brazil, until its fusion with the Fundação Serviços Especiais de Saúde Pública, SESP, giving place to the Fundação Nacional de
Saúde - FNS or FUNASA) had "eradicated" P. malariae from Brazil in the 1980s simply by switching the method of diagnosis from thin to thick smear, the only official method for malaria diagnosis in Brazil. Indeed, with this procedure it is not possible to assess the morphology of infected red blood cells and the parasite-altered shape can lead to a mistaken identification of $P$. malariae as $P$. vivax. Therefore, the failure to report $P$. malariae in endemic areas is not surprising. Studies on antibody response to $P$. malariae CS protein and the use of nested polymerase chain reaction suggest that this parasite could possibly be more prevalent in scattered areas, at least in the populations studied in Rondônia, Amazonas and Pará States $[14,15]$. However, no case of $P$. malariae infection was found by PCR among febrile patients in Manaus [16].

Even if considering that the incidence of $P$. malariae in Brazil may be underestimated, it is worth mentioning that predominant incidence of $P$. vivax malaria is a quite recent phenomenon (since the early 1990s) and results from, or has been at least very probably reinforced by, the pressure exerted by the PNCM aiming at the early diagnosis and treatment of cases. Indeed, since $P$. falciparum gametocytes appear in the peripheral blood only after 8 to 10 days of infection, prompt diagnosis and adequate treatment of the falciparum malaria cases can interrupt parasite transmission more efficiently, than in the case of $P$. vivax malaria, in which gametocytes are already present in the circulation in the first three days of blood infection [17]. Thus, the relative incidence of the two main Plasmodium species transmitted in Brazil was around $50 \%$ each in 1988. This changed from 1990 onwards (when $44.3 \%$ of cases were due to $P$. falciparum), reaching the situation in 2009 when $P$. vivax has become the predominant species (only $16,3 \%$ of cases being due to $P$. falciparum)(Figure 3).

\section{The decreasing occurrence of severe malaria in Brazil}

Plasmodium vivax is thought to cause little mortality but, as $P$. falciparum, it accounts for a vast amount of morbidity and for a huge burden on the prosperity of endemic communities. Probably as a result of the early diagnosis and treatment of the cases and of the decrease in P. falciparum transmission, the number of hospitalizations due to malaria dropped (53,450 in 1994 to 18037 in 2000 and 4,442 in 2009) as did the number of registered deaths attributed to the disease (from 897 in 1984 to 58 in 2009), together with the fatality rate (from $0.038 \%$ in 2000 to $0.013 \%$ in 2009) in the Amazon (Figure 4). This is probably a direct result of the early diagnosis and treatment of the malaria cases as a consequence of the already mentioned expansion of the network of Laboratory and Health Agents in the Amazon. In fact, $59 \%$ of all malaria cases registered in 2008 in the region were treated in the first 48 hours after appearance of symptoms [10], dimin- 


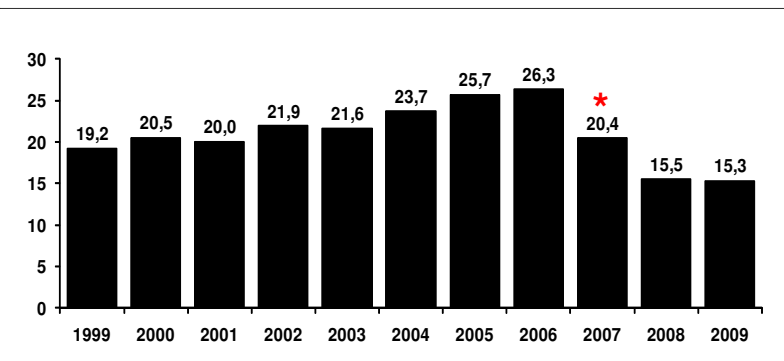

Figure 3 Evolution of the proportion of malaria cases due to Plasmodium falciparum in the Amazon from the year of 1999 to 2009. Since $P$. falciparum gametocytes only appear in the peripheral blood after 8 to 10 days of infection, prompt diagnosis and adequate treatment of the $P$. falciparum malaria cases can interrupt parasite transmission more efficiently than it can do in the case of $P$. vivax malaria, in which gametocytes are already present in the circulation in the first three days of blood infection [15]. * Beginning of the new therapy artemether/lumefantrine, the first line regimen for non-complicated falciparum malaria in Brazil. Source: Sivep - Malaria - Data updated on September 9th, 2008.

ishing both the transmission and the occurrence of complicated cases in endemic areas.

In one illustrative example of the present situation, as far as malaria morbidity in Brazil is concerned, Fernandes et al [18] studied 127 P. falciparum and $74 P$. vivax malaria patients in two localities (Belém and Paragominas) of the Amazonian State of Pará and could find only one case of severe anaemia (associated to $P$. vivax and not to $P$. falciparum infection). No other malaria patient enrolled in the study was hospitalized due to anaemia or for any other reason. The low frequency of hospitalization observed during the period of the study (2001 to 2003) was in accordance with the overall picture recorded

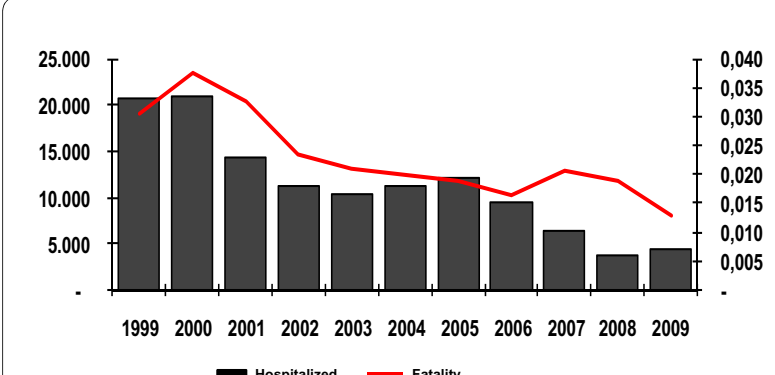

Figure 4 Malaria fatality rates and number of hospitalizations due to the disease in the Brazilian Amazon from 1999 to 2009. The number of hospitalizations due to malaria in the Brazilian Amazon dropped from 53,450 in 1994 to 18,037 in 2000 and 4,442 in 2009 as did the number of registered deaths attributed to the disease (from 897 in 1984 to 58 in 2009) as well as the fatality rate (from $0.038 \%$ in 2000 to $0.013 \%$ in 2009). The malaria cases seen in Brazil are being rapidly diagnosed and treated (59\% of all malaria cases in 2008 registered in the Amazon were treated in the first 48 hours after appearance of symptoms, Malaria/SVS/MS, 2009), diminishing both the transmission and the occurrence of severe cases. for the state of Pará in the same period, when there was a sharp reduction in the total number of malaria cases $(279,303$ in 2000 and 123,490 in 2003) and in the frequency of hospitalization (3.3\% in 2000 and $2.6 \%$ in 2003) [19]. The absolute number of hospitalized patients from 2000 to 2003 in Belém dropped drastically as well (140 hospitalized patients in 2000 and 49 in 2003) and particularly in Paragominas (275 in 2000 and only six in 2003). In the same way, the mortality due to malaria in 2001 to 2003 was low, with a total of 119 fatal cases out of 458,305 malaria cases $[0.26$ fatal outcomes per 1000 malaria cases, or 10.2 deaths per 1000 hospitalized patients [Rui Bráz and Carlos José Mangabeira-Silva (PNCM-SVS/ MS), personal communication]. Similar data were presented by Caicedo et al [20], who found that severe anaemia was rare amongst patients from two distinct malaria endemic areas in Manaus (Brazil) and Tumaco (Colombia).

In spite of the decreasing severity of malaria observed in Brazil in the last years, one point that merits to be emphasized, is that, precisely as a result of the concentration of malaria in the Amazon region, general practitioners outside the Amazon region are much less alert to consider the diagnosis of malaria, when facing a febrile patient. Migration and international travel require personnel with specific expertise, highlighting the importance of the specialty of Infectious Diseases and the sentinel surveillance of febrile travelers. One illustrative example would be the already reported frequent confusion of malaria with dengue in the city of Rio de Janeiro [21]. Visitors from Africa might die of falciparum malaria about seven days after the beginning of the symptomatology, with more than half of all erythrocytes parasitized [22]. These are probably the reasons why malaria lethality is more than seventy times higher in this region $(1,27 \%)$ than in the Amazon (0,018\%)[10]. It is noteworthy that most of the travelers' clinics in Brazil are concentrated in Rio de Janeiro and São Paulo states.

In summary, the inversion of the P. falciparum/P. vivax cases ratio in Brazil in the last two decades was a major achievement of the National Control Programme, leading to a substantial decrease in the number of deaths. However, this may be troublesome regarding the future perspectives of eliminating malaria in Brazil, since policymakers are less prone to privilege investments in a disease with low fatality rates and with a massive incidence outside the economic axis area of the country. Some neglected effects of the 'benign' $P$. vivax infection must be considered because they may compromise the development of endemic countries, such as the impact upon school performance, as recently shown in children from an endemic area in the Amazonas State [23]. In addition, vivax malaria may not always be benign [10]. 


\section{Unusual clinical complications associated with P. vivax in the Brazilian Amazon}

Plasmodium vivax infection is generally recognized in the literature as a benign disease, despite triggering fever with a lower peripheral parasitaemia, as compared to $P$. falciparum [24]. However, in the last few years a pattern of unusual clinical complications with fatal cases associated with $P$. vivax have been reported in Brazil and is a matter of concern for Brazilian malariologists [25,26]. It is difficult to assume that there has been a worldwide increase of severity associated with $P$. vivax infection. Although most of the publications had previously been biased towards P. falciparum infection and its associated severity in the African continent, where most of the deaths are concentrated, more recently some attention has been devoted to the burden of the complicated $P$. vivax disease in Southeast Asia [27] and Latin America [28].

In Brazil, importantly and curiously, paralleling the increase in the proportion of $P$. vivax malaria recorded from the middle of 1980s to the beginning of the 1990s, an increase in the frequency of unusual clinical complications in $P$. vivax infected patients has been observed in the Amazon. According to the official statistics, from 1998 to 2008, 234 deaths related to $P$. vivax infection were reported in the Brazilian Amazon [10,29]. However, one must keep in mind that the description of a severe case and, even more, of a fatal case of $P$. vivax malaria requires, as a sine qua non condition, the confirmation of the involved species using a highly sensitive approach (e.g., PCR) to eliminate the possibility of a mixed (P. falciparum/P. vivax) infection and to rule out the presence of other simultaneous acute infectious diseases (e.g., dengue, yellow fever and other Amazonian virus - such as Oropoupouch and Mayaro, leptospirosis, typhoid fever, sepsis), as well as other chronic diseases, such as sickle cell anaemia, which may decompensate as a result of the $P$. vivax infection [25]. Likewise, fatal cases must ideally be submitted to a full autopsy allowing the characterization of its major anatomo-pathological findings. Despite representing a very low fatality rate, such severe cases were not reported when $P$. falciparum was the predominant species in Brazil. They may be associated to an increased exposure of non-immune population to this species, leading to the occurrence of severe $P$. vivax infection, similar to what was observed in the north-west of India, in Rajhastan, where severe $P$. vivax cases started to show up only after the inversion in the $P$. falciparum $/ P$. vivax cases ratio [30,31].

The proportion of hospitalized cases due to $P$. falciparum decreased from $29 \%$ in 2003 to $25 \%$ in 2008, those due to an increase of P. vivax from $38 \%$ to $49 \%$ [10]. While the number of lethal cases of vivax malaria is stable since 2001 (around 21 cases/annum), the decrease in malaria transmission and in the absolute number of registered cases of vivax malaria since 2005 result in a mild but regular increase in the fatality rate in the last years, the highest rate having been observed in 2008 (0.008\%)(Figure 4).

Manaus, the capital of the Amazonas State, is one of the three municipalities that, together with Porto Velho (Rondônia State) and Cruzeiro do Sul (Acre State) accounted for about one fifth of the total number of cases notified in Brazil in 2008 [10]. In Manaus, the Fundação de Medicina Tropical do Amazonas (FMT-AM) - that serves as a reference centre for health care and research on tropical diseases and diagnoses - treats around 30\% of the malaria cases seen in this municipality. In Manaus, the total number of hospitalized $P$. vivax malaria cases as well as the proportion of the hospitalized cases due to this species (in relation to P. falciparum) seems to be increasing in the FMT-AM [32]. The major complication found in patients with $P$. vivax infection is thrombocytopenia, which accounts for $20 \%$ of the admissions to this tertiary care hospital in Manaus [26,33]. In the majority of the cases, severe thrombocytopenia $(<50000$ platelets $/ \mathrm{mm}^{3}$ ) is not associated with coagulation disorders, such as disseminated intravascular coagulation [34]. In Manaus, severe thrombocytopenia was found in $8.9 \%$ of the patients with $P$. vivax infection, with only bleeding in one fourth of them (Lacerda MVG, unpublished data). The clinical relevance of this haematological complication, however, needs further clinical studies, as well as for $P$. falciparum, since there is no reported fatal case of malaria presenting exclusively with severe thrombocytopenia. Other relevant clinical complications include patients developing immune thrombocytopenic purpura after curing the infection [35] and splenic haematoma [36]. In non-endemic areas of malaria in Brazil, such as São Paulo, severe cases of $P$. vivax infection are being reported in travelers [37], and thrombocytopenia is often misattributed to dengue infection in Rio de Janeiro, where the disease is endemic [38]

At the FMT-AM, in a retrospective study from 2001 to 2002, applying the WHO criteria of malaria severity (traditionally used for P. falciparum malaria), $12.8 \%$ of the patients were diagnosed as having severe $P$. vivax malaria (43 out of 336 patients hospitalized with $P$. vivax malaria during the period). The clinical complications were very similar to those associated with $P$. falciparum infection, e.g., hyperbilirrubinaemia, severe anaemia, acute renal failure, pulmonary edema and algid malaria [39]. In a series of cases with the parasitological diagnosis of $P$. vivax infection, which evolved to death in the same institution and were submitted to a full autopsy, the major findings were acute tubular necrosis, pulmonary edema and pneumonia (Lacerda MVG, unpublished data). Most of the patients who died presented other co-morbidity that could have contributed to the death, such as chronic 
liver disease, cardiac disease and G6PD deficiency. Series of severe cases have also been reported in other endemic areas for $P$. vivax malaria [30,40], but no standardized criteria are being routinely used for the clinical description of such cases in the literature.

Although this is not in the scope of this overview, it is important to briefly consider some aspects of the treatment of $P$. vivax malaria, which is no longer a simple task in many parts of the world, including Brazil. For instance, the radical cure of hypnozoites with primaquine (the only hypnozoiticidal drug currently approved for clinical use), almost always feasible with the shorter regimen of $30 \mathrm{mg} /$ day for seven days in adults currently used un Brazil, may require the classical long-term (14 day) regimen [41]. With the increase in the number of $P$. vivax infections, the widespread use of primaquine for the radical cure may trigger severe complications (such as haemolysis and methaemoglobinaemia) in patients deficient for G6PD, which frequency is around 3\% among males in Manaus [42]. These complications can be mistaken as a complication of $P$. vivax per se [43].

There is also in vivo evidence for the resistance of $P$. vivax to chloroquine in the Brazilian Amazon [44]. The resistance to chloroquine was firstly reported in Manaus in 1999 [45] and more recent data, from studies conducted in the context of the RAVREDA (Amazonian Network for Surveillance for Resistance to Antimalarial Drugs) with a proper follow-up of patients exclusively using chloroquine and in whom the drug plasma concentration was performed, seem to confirm such an observation [46]. However, since chloroquine plus primaquine, the drug association used for the radical cure of $P$. vivax infection, have a synergistic action [47], further studies are needed before any definitive conclusion can be proposed. Such studies should include non-endemic areas where the chance of reinfection is minimal and the potential for monitoring real resistance to both drugs is enhanced.

\section{Malaria outside the Amazon region and the "bromeliad- malaria"}

As an expected consequence of the existence of some thousands of malaria cases in the Amazon basin, a few cases do occur also outside the area of active transmission. Some of them correspond to autochthonous cases of malaria transmitted and maintained in small foci of transmission with very specific characteristics, such as those reported in the Atlantic Forest. The historical series of autochthonous cases outside the Amazon region is presented in Figure 5, showing a huge increase in the numbers in 2002 due to an outbreak of $P$. falciparum malaria occurred in the Ceará State, north-eastern Brazil.

Considering the State of Rio de Janeiro, where the headquarters of Fundação Oswaldo Cruz and CPD-Mal

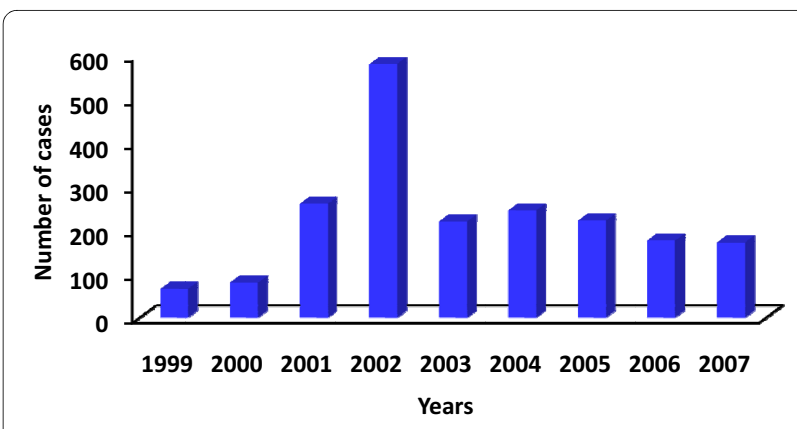

Figure 5 Number of cases of autochthonous malaria seen outside the Amazon region. The peak registered in 2002 is due to an outbreak of Plasmodium falciparum malaria observed in the State of Ceará, Northwestern Brazil. Cases seen outside the Amazon are mainly due to the transmission by Anopheles (Kertezia) occurring in the Atlantic forest possibly maintained by the involvement of infection of monkeys.

(the Reference Center for Malaria at the Secretary of Health Surveillance at the Ministry of Health) are located, a total of 1,505 malaria cases were reported from 1990 to 2008 (79 cases/year). Rio de Janeiro is the most visited city in Brazil (two million of tourists annually) and the home of $20 \%$ of all Brazilians who travel abroad for leisure or business. Probably as a result of this, most of malaria cases seen in the city are expected to be imported from the Amazon region and Africa. However, in the 20012008 period, $30 \%$ of the 29 reported autochthonous cases in Rio de Janeiro originated from Nova Friburgo, a mountain region in the Atlantic Forest. In the 2006-2008 period, three cases, diagnosed (by thick blood Smear, and PCR) as $P$. vivax malaria, came from localities situated between the municipalities of Nova Friburgo and Guapimirim at the "Serra dos Órgãos", also in the Atlantic Region. Patients presented at the Acute Febrile Diseases Outpatient Clinics of the Instituto de Pesquisa Clinica Evandro Chagas (a branch of the CPD-Mal at Fiocruz) with low parasite (P. vivax) counts and mild symptoms including low-grade $\left(<38^{\circ} \mathrm{C}\right)$ fever and splenomegaly [38]. Mild atypical symptomatology and very low parasitaemia was also the predominant presenting form of the disease in the autochthonous $P$. vivax malaria reported in inhabitants of two parks in the Atlantic forest of the São Paulo State between 1990 and 2000 [48,49]. Little is known about the factors involved in the chain of native transmission of malaria in the Atlantic region and malaria outbreaks in the Atlantic forest of Rio de Janeiro are not new events. Serological and entomological surveys performed in 1993 and 1996 in a village situated in a mountain valley: Rio Bonito in Rio de Janeiro state, where an outbreak of vivax malaria had occurred, suggested that Anopheles (Kerteszia) cruzii was a potential vector of malaria in this region [50]. At that time, one of the hypotheses was that members of a group of religious sects originating from the Amazon and constantly visit- 
ing the Amazon region could be responsible for the introduction of malaria in the district of Lumiar (Rio de Janeiro). The installation of a timber factory in Friburgo, working with products of trees brought from the Amazon region, points to another possibility for carrying mosquitoes as foci of infection.

Deane [51] suggested that simian Plasmodium species could be responsible for these cases of malaria known as "bromeliad-malaria" in forest areas, where monkeys of the genera Allouata and Cebus and the Anopheles (Kertesia) cruzii and Anopheles (Kertezia) bellator, which breed in the water collections formed inside the bromeliads, are present. The presence of malaria in people coming into such areas of dense forest could ensure both simian and human malaria transmission. Duarte and coworkers [52] showed the occurrence of malaria parasites and serological responses against asexual forms and synthetic peptides mimicking the immunodominant epitope of the circumsporozoite protein (CS protein) of human malaria parasites in wild monkeys from areas of autochthonous human malaria. The existence of $P$. vivax variants and simian malaria in the Atlantic forest of Rio de Janeiro and Espirito Santo States also points to the possibility that monkeys could be the natural reservoir for malaria in the Atlantic forest and explain the autochthonous cases registered (Figure 6)[48,50,53]. Recent studies have shown that the simian malaria $P$. knowlesi in the human host is not rare, is widely distributed and can result in severe disease and death in humans, particularly in areas inhabited by the natural macaque host [54]. Taken together these data support the view that malaria transmission from neotropical primates to humans, and vice versa, may also occur more frequently than currently believed, both in the Amazonian rainforest and in the Atlantic forest.

The interruption of transmission of the "bromeliadmalaria", which occurred during the years 1980 to 1982 in the state of Santa Catarina - southern Brazil, was important and a good example that alternative control measures may be required to the control of residual malaria in an given area [55]. The transmission was restricted to two municipalities (São Francisco do Sul and Taquari) in that state and had never been interrupted, despite many efforts. In these two municipalities with a population of thirty thousand people, one thousand and six hundred autochthonous cases occurred each year, mainly in adults males under 50 years old. The transmission was seasonal, from November to April and all cases were due to $P$. vivax. The main vector was An. cruzii, which usually bites animals and humans outside houses. The use of DDT spraying inside the houses - a traditional measure in the control of malaria - was rejected by a high proportion of people, because its ineffectiveness, and because other interventions previously used, such as mechanical and chemical massive destruction of bromeliads, were also ineffective. The hypothesis that monkeys could be an eventual reservoir maintaining the parasites from May to October was discarded since they were not found in the area. Therefore, other hypotheses were considered to explain the maintenance of the circulation of parasite in humans in those localities. They included the presence of either asymptomatic $P$. vivax infections - patients with very low parasitaemia undiagnosed by microscopic examination - or of a $P$. vivax strain (already described in temperate climates) with long-term incubation period. A sero-epidemiological survey was performed with the aim of identifying parasite-carriers needing to be treated [56]. In 1980, around twenty seven thousand blood samples were collected on filter paper and sent to be processed in the SUCEN Laboratory at São Paulo. About five hundred people presented antibody (as revealed by anti-human total Ig antibodies) titres over 1:64 and were treated with chloroquine plus primaquine. In the following year, only twenty cases were diagnosed. In 1982, the sero-epidemiological survey was repeated, and two hundred cases were considered positive, with IgM/IgG over 1:64. They were treated and until now, about 27 years later, no more autochthonous cases were registered in the area.

If, on the one hand, studies conducted in the neighbouring states of São Paulo and Espírito Santo confirmed, using serological or molecular approaches, the asymptomatic infection by Plasmodium in areas outside the Amazon region, the lack of investigation of indigenous malaria cases in the state of Rio de Janeiro, on the other hand, does not give any information on what actually happens in the region (Figure 6). Further investigations are needed to confirm the presence of asymptomatic Plasmodium-infected individuals in the Atlantic region, since transfusion malaria is rarely diagnosed, but does occur and can become an important concern to medical services and health authorities [57].

Finally, it is important to emphasize to those involved in giving international travel advice that, excepting for the examples given above, which concern specific localities of the Atlantic forest and must be considered rare events, malaria transmission does not occur outside the Brazilian Amazon. Therefore, anti-malarial chemoprophylaxis is neither needed nor recommended by the Brazilian Ministry of Health or the WHO to those visiting exclusively areas outside the Amazon Region. Thus, the visitors attending the Olympic Games of Rio de Janeiro in 2016 will not need to be submitted to the side effects of antimalarials throughout their stay in the city.

\section{Some information arisen from the study of the naturally acquired immunity}

The pattern of malaria transmission in Latin America is different from that in the endemic areas of Africa. In Brazil, malaria is endemic in the Amazon region and is fre- 


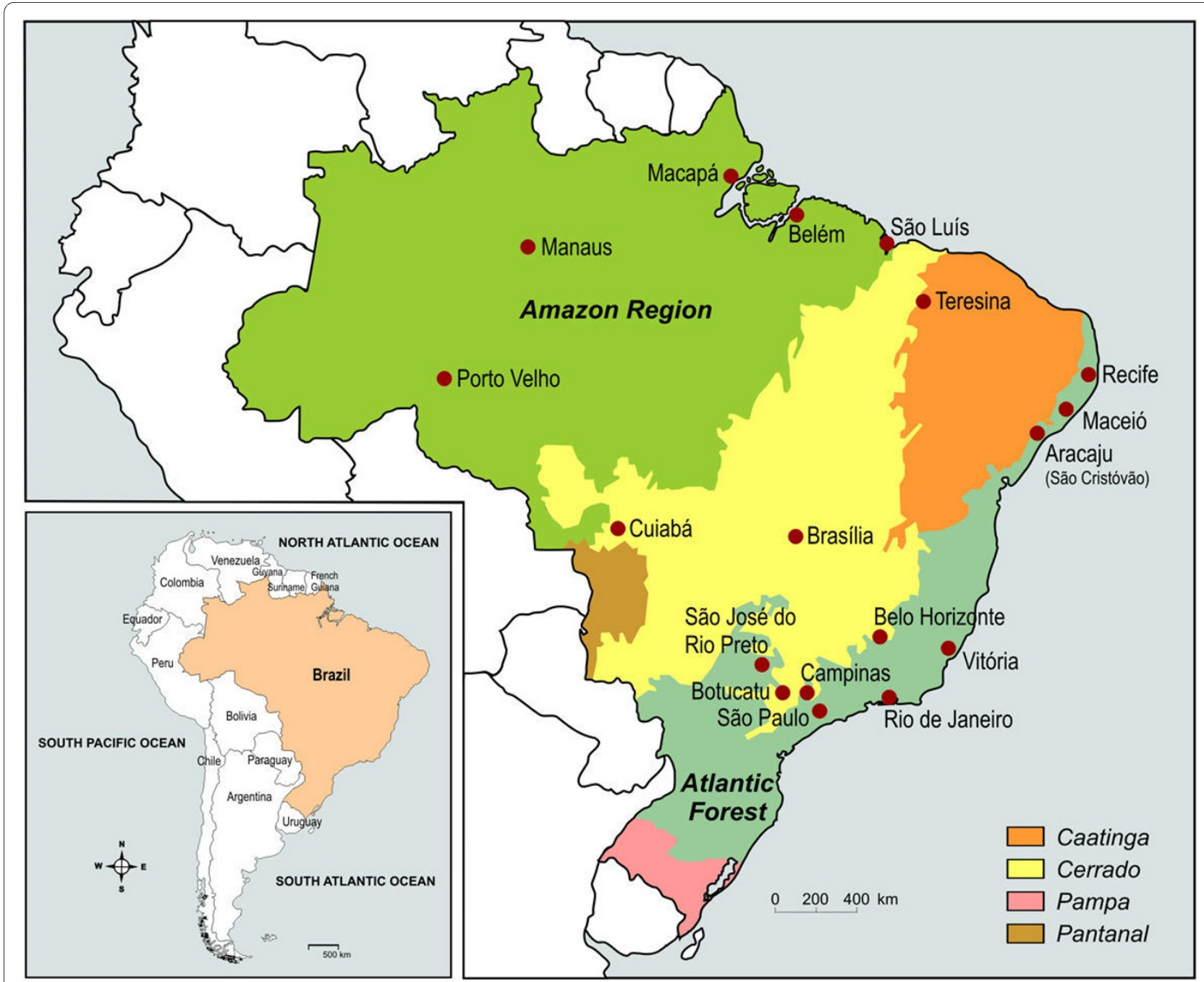

Figure 6 The Brazilian Biome Map and location of Research Centres. The Amazon region covers 40\% of the surface of South America and 5\% of the surface of the world, and $61 \%$ of its territory is in Brazil. It has the largest hydrographic network on earth, covering $20 \%$ of the worlds fresh water reserves and shelter the largest number of life forms on earth; the Atlantic forest (seasonal semideciduous forests) is the third largest Brazilian biome that stretches for about 4000 km along the Atlantic coast between Rio Grande do Norte and Rio Grande do Sul; the "Caatinga" (semiarid steppe of Northeast Brazil) is located on the north-east coast is the largest dry forest region in South America and characterized by a semi-arid climate, low and unregular rainfall, fertile soils and an apparently dry vegetation; the Cerrado (Brazilian Savanna) is located on the large plateau that occupies the central highlands. Influenced by the four surrounding biomes, the fauna and flora of the Cerrado is extremely rich and the climate is hot and semi-humid; the Pantanal (Brazilian wetlands) is located in the watershed of the Upper Paraguay Rivers the largest area of fresh water marshes in the world, shared between Brazil (60\%), Bolivia and Paraguay. The Pampas are the fertile South American lowlands in the southernmost end of Brazil, the climate is mild and contain unique wildlife because of the different terrains around it.

quently associated with migration movements of nonimmune individuals to areas where malaria is endemic. The population exposed to malaria in these areas, regardless of age, is vulnerable and infections tend to be followed by clinical symptoms [6,58]. For a long time, asymptomatic cases have been considered rare in Brazil [59]. However, asymptomatic infection by $P$. falciparum and $P$. vivax were detected in studies in the states of Rondonia and Amazonas, suggesting that subjects exposed to malaria in Brazil also develop acquired resistance to clini- cal malaria despite the epidemiological profile different from the one seen in Africa [60-63].

It is well-established that acquired clinical immunity to P. falciparum malaria depends on long-term repeated exposure to the parasite, a conclusion based on the observation that effective natural immunity to this species is restricted to areas of high level of transmission and endemicity, where age has always been considered to reflect the degree of exposure. It is now known, however, that non-immune adult migrants can naturally acquire reasonable clinical immunity more rapidly and efficiently 
than children, probably reflecting a different maturity of the immune system [64].

Studies on acquired immune responses against $P$. falciparum of individuals naturally-exposed who live in endemic areas of Brazil show that individuals primed against $P$. falciparum in their natural habitat, present a very diverse array of responses against $P$. falciparum antigens, varying from low to high $B$ and $T$ cell responses and indicating that the immune response to most of antigens can be used to assess malaria transmission in epidemiological surveys. Very few of such studies show an association with clinical immunity [65-74].

Evidence that the protective immunity to $P$. falciparum malaria is associated with different classes and subclasses of antibodies reveals the importance of considering the quality of the response. In Brazil, analysis of the antibody isotypes specific for several $P$. falciparum proteins revealed that all four IgG subclasses are present and, for some proteins such as the $\mathrm{N}$-terminal region of the p126 protein, individuals with higher levels of anti-Nt47 cytophilic IgG antibody had significantly lower parasitaemia levels [68]. In contrast, plasma concentrations of IgG against a detergent-soluble extract of $P$. falciparum schizonts, the concentrations of anti-parasite antibodies of all subclasses increased with age. There was no correlation between age and the proportion of cytophilic antibodies [75] and no major difference was observed in IgG subclass distribution of antibodies to the polymorphic block 2 and the 19-kDa C-terminal domain MSP-1 between symptomatic, and asymptomatic parasite carriers [71].

The presence of asymptomatic infections in Amazonian communities suggests that, in fact, a similar phenomenon may be occurring in areas of low P. vivax transmission in Brazil. The gradual nature of the acquisition of this immunity is known to be partially mediated by malaria specific antibodies responses, since passive transfer of purified immunoglobulin from immune individuals rapidly reduces the recipient's parasitaemia [76]. Despite this, the factors that govern the development of acquired immunity after natural infection remain poorly understood. The identification of parasite antigens that induce protective antibody and cellular responses would be an important step toward understanding of naturally acquired immunity to $P$. vivax malaria.

In Brazil, naturally occurring antibody to $P$. vivax sporozoites have been reported since the late 1980s in indigenous population in the State of Para Brazil [77]. Since then, polymorphism of the $P$. vivax CS protein of $P$. vivax was reported and, in addition to parasites with the original CS repeat amino acid sequences, designated $P$. vivax VK210, a variant VK247 and $P$. vivax-like was also described [78,79]. The human $P$. vivax-like parasite has a CS repeat which corresponds to the simian parasite $P$. simiovale. Otherwise the identity of these parasites is not clear, since a line of the human isolates has not yet been obtained and the clinical manifestation of this infection, as well as that of VK247 variant is unknown.

In view of this finding, blood samples from the indigenous population mentioned above were re-examined and high level of reactivity against the variants were detected. These results demonstrated that these variants have been present in Amazonian Indians for at least 12 years [80]. Other studies showed the occurrence of $P$. vivax variants both by serology and PCR reaction in samples from different endemic regions in Brazil $[14,48,81,82]$. In nonendemic regions, $P$. vivax and variants have been also detected.

Studies on the naturally acquired humoral immune responses to several $P$. vivax blood stage vaccine candidates, such as PvMSP-1 (Merozoite Surface Protein 1), PvAMA-1 (Apical Membrane Antigen 1), PvMSP-3 (Merozoite Surface Protein 3); PvMSP-9 (Merozoite Surface Protein 9, RBP (Reticulocyte Binding Protein) and DBP (Duffy Binding Protein) show that they are immunogenic in distinct Brazilian endemic areas with different levels of exposure [63,74,83-91]. The specific antibodies induced by natural infections to most of the proteins are associated with time of exposure in endemic regions, a phenomenon which has been frequently reported for various antigens reflecting most likely exposure to the parasites and possibly maturation of the immune system over time. Although there is consistent evidence from human and animal model system that cell-mediated immunity may contribute both to protection and to pathogenesis, the knowledge on cellular immune response in vivax malaria and the factors that may regulate this immunity are still poorly understood [92]. Very few studies have been able to find a clear association between specific cellular and antibodies to vaccine candidates and protection. However, direct comparison of natural cellular and antibodies responses to $P$. vivax antigens may provide valuable insight as to how a malaria vaccine might work. Probably, an accumulation of a comprehensive repertoire of antibodies recognizing antigenically distinct molecules may be the key to acquisition of clinical protection.

\section{Malaria research and teaching in Brazil}

A survey of the groups working on different aspects of malaria in Brazil was made in 2007 to facilitate and promote contacts with malariologists outside Brazil [93]. A total of 70 groups were identified. From these, 46 were considered to be effectively involved in conducting research on malariology. Groups working with other approaches, such as clinical, control, information, prevention and therapeutics, without being, however, directly concerned with research have also been listed. The catalogue included a comprehensive classification of 
the groups, according to the themes of interest and expertise (considering that a group could be competent and interested in more than on subject. Five groups were working on biochemistry (including organic synthesis and medicinal chemistry), five on cell biology, 15 on clinical aspects, nine on diagnosis, 30 on drugs and therapeutics (natural products, perspectives for drug development, pharmacology, prophylaxis, chemo-resistance and response monitoring), 17 on entomology and vector control, 34 on epidemiology and control, 16 on genetics and molecular biology (including recombinant proteins and genetic polymorphisms), 19 on immunology (immune protection, immune response, immunomodulation, immunopathology and vaccine development and testing in preclinical trials), five on parasitology and six on pathogenesis and pathology.

It is important to point out that only 19\% of these research centres are located in the Amazon region (Figure 6). Despite occupying more than half (58\%) of the country territorial surface (approximately 8,511,965 square kilometers) and concentrating $99,8 \%$ of the registered cases of malaria, the region hosts only around $8 \%$ of the urban and $12 \%$ of the total population of the country, $10 \%$ of the electorate in Brazil and accounts for about 5 percent of the nation's gross national product [94]. A volume of the catalogue can be obtained by request to the corresponding author (CTDR).

Some teaching activities focusing specifically on malariology are offered to students and graduates in Brazil. Courses on host-parasite relationship, parasitology or tropical medicine, that cover malaria together with other parasitic and infectious diseases in the programme, are not considered here. A two-week course (including practical classes on parasitological examination of blood films) is offered yearly (in November) by the team of the CPD-Mal to post-graduate (PG)(MSc and PhD) students from the courses of IOC at Fiocruz and from other institutions [95]. A three-week course, also directed to PG students (Course on Infectious and Parasitic Diseases at the Faculty of Medicine of the University of São Paulo FM-USP, takes place at a biennial rhythm at the Instituto de Medicina Tropical de São Paulo and is also opened to students and graduates from other institutions [96]. A one-week course on control of malaria vector, with emphasis on biological control and practical field activities is offered yearly at the Instituto Nacional de Pesquisas da Amazônia (end of October beginning November)[97].

The Seminário Laveran E Deane sobre Malária is organized yearly by the CPD-Mal/Fiocruz, since 1995, to analyze and improve the project thesis of MSc and $\mathrm{PhD}$ Brazilian students. The participants are confined in a hotel (on the Itacuruçá Island) for five days, when the projects are presented and discussed both in plenary and in group discussion sections. Each student has two senior tutors that follow the student for the duration of the seminar, helping him/her in the composition of his/her final report. The body of Professors also proposes a final Senior Report to each student. The Seminário is supported mainly by the PNCM (as well as by the CNPq and Faperj, and has also financial help from the French Government and the Sanofi-Aventis Impact Malaria Initiative). The full methodology and a detailed description of the dynamics of the Seminário can be found at its website [95].

\section{Competing interests \\ The authors declare that they have no competing interests.}

\section{Authors' contributions}

JOF summarized the work done on malaria immunity and data on malaria in the Atlantic Forest and wrote the corresponding texts, prepared the final presentation of figures and organized the final text together with CTDR, MVGL worked with data on severe malaria and on hospitalized patients in the Amazon Region and wrote, together with JLBL and PT the perspectives on control of the disease, PB worked mainly with data concerning outpatient clinics and hospitalized patients from the Extra-Amazon region and data on autochthonous malaria in the Atlantic Forest, in Rio de Janeiro, JLBL and PT provided data on the present situation as well as historical information about malaria in the Country. CTDR planned and coordinated the article, choose the figures, dealt with data on immunity, clinical and historical aspects and reviewed and organized the final document with JOF. All authors read and approved the final manuscript.

\section{Acknowledgements}

The authors wish to thank Professor Cór Jésus Fontes (Universidade do Mato Grosso) for critically reviewing the manuscript. We are also indebted to Doctors Carlos José Mangabeira da Silva and Rui Moreira Braz (from the National Programme for Malaria Control, SVS - Brasília) for providing data on malaria transmission, morbidity and mortality in the Amazon. CTDR is recipient of a "Research Productivity" fellowship from the Conselho Nacional de Desenvolvimento Científico e Tecnológico (CNPq) and is a Cientista do Nosso Estado from Fundação de Amparo à Pesquisa do Estado do Rio de Janeiro (Faperj), Brazil.

\section{Author Details}

'Laboratório de Pesquisa em Malária, Instituto Oswaldo Cruz, Fiocruz, Pavilhão Leônidas Deane - $5^{\circ}$ andar, Av. Brasil 4365, Manguinhos, Rio de Janeiro, RJ - CEP 21.045-900, RJ - Brazil, ${ }^{2}$ Centro de Pesquisa Diagnóstico e Treinamento em Malária (CPD-Mal), Fiocruz and Secretaria de Vigilância em Saúde (SVS) -

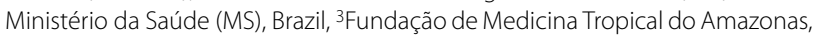
Av. Pedro Teixeira 25, Manaus, Amazonas - CEP 69.040-000, Brazil, 4 Instituto de Pesquisa Clínica Evandro Chagas, Fiocruz, Av. Brasil 4365. Manguinhos, Rio de Janeiro, RJ - CEP 21.045-900, RJ - Brazil, ${ }^{5}$ Programa Nacional de Controle da Malária, SVS-MS, Esplanada dos Ministérios, Bloco G, Sobreloja, sala 151. Brasília - CEP 70.058-900, Brazil, ${ }^{\circ}$ Área de Medicina Social, Faculdade de Medicina, Universidade de Brasília, Brasília - CEP 70.910-900, Brazil and `Laboratório de Imunoparasitologia, Instituto Oswaldo Cruz, Fiocruz. Pavilhão Leônidas Deane $4^{\circ}$ andar. Av. Brasil 4365. Manguinhos, Rio de Janeiro, RJ - CEP 21.045-900, RJ Brazil

Received: 29 December 2009 Accepted: 30 April 2010 Published: 30 April 2010

\section{References}

1. Deane L: Os grandes marcos na história do controle da malaria. RevSoc Bras Med Trop 1992, 25(Suppl II):12-22.

2. Barros-Barreto J: Malaria: doutrina e prática. Rio de Janeiro: Editora a noite; 1940

3. Tauil P, Daniel-Ribeiro C: Some aspects of epidemiology and control of malaria in Brazil. Res Rev Parasitol 1998, 58:163-167.

4. Loiola CC, da Silva CJ, Tauil PL: Malaria control in Brazil: 1965 to 2001. Rev Panam Salud Publica 2002, 11(4):235-244. 
5. Marques AC: Migrações internas e grandes endemias. Revista Brasileira de Malariologia e Doenças Tropicais 1979, 31:137-158.

6. Marques AC: Human migration and the spread of malaria in Brazil. Parasitol Today 1987, 3:166-170.

7. Marques AC: Um estudo sobre a dispersão de casos de malária no Brasil. Revista Brasileira de Malariologia e Doenças Tropicais 1986, 38:51-75.

8. OMS: Aplication de la Estrategia Mundial de Lucha contra el Paludismo. Informe de Estudio de la OMS sobre la Application del Plan Mundial de Acción contra el Paludismo, 1993-2000 1993:61.

9. Barata RC: Malaria in Brazil: trends in the last ten years. Cad de Saude Publica 1995, 11:128-136.

10. Malaria/SVS/MS: Malária in "Doenças de A a Z". 2009 [http:// portalsaudegovbr/portal/saude/profissional/areacfm?id area=1526 SVS/Ministério da Saúde

11. Macauley C: Aggressive active case detection: a malaria control strategy based on the Brazilian model. Soc Sci Med 2005, 60:563-573.

12. Martinez-Espinosa FE, Alecrim WD, Daniel-Ribeiro CT: Malária durante a gravidez na região Amazônica: diagnóstico por sintomas da infecção em mulheres de idade fértil em Coari, Amazonas em 2001-2002. Rev Soc BrasMed Trop 2005, 38(suppl I):362.

13. Gonçalves MJF, Alecrim WD: Non-planed urbaniztion as a contributing factor for malaria incidence in Manaus-Amazonas, Brazil. Rev Salud Publica (Bogota) 2004, 6:156-166

14. Arruda ME, Zimmerman RH, Souza RM, Oliveira-Ferreira J: Prevalence and level of antibodies to the circumsporozoite protein of human malaria parasites in five states of the Amazon region of Brazil. Mem Inst Oswaldo Cruz 2007, 102:367-371.

15. Cavasini MT, Ribeiro WL, Kawamoto F, Ferreira MU: How prevalent is Plasmodium malariae in Rondonia, western Brazilian Amazon? Rev Soc Bras Med Trop 2000, 33:489-492.

16. Costa MR, Vieira PP, Ferreira Cde O, Lacerda MV, Alecrim WD, Alecrim MG: [Molecular diagnosing of malaria in a tertiary care center in the Brazilian Amazon region](in Portuguese). Rev Soc Bras Med Trop 2008, 41:381-385.

17. Bruce-Chwatt L: Essential Malariology 2nd edition. New York: John Wiley \& Sons; 1985.

18. Fernandes AAM, Carvalho LJD, Zanini GM, Ventura AMRD, Souza JM, Cotias PM, Silva IL, Daniel-Ribeiro CT: Similar cytokine responses and degrees of anemia in patients with Plasmodium falciparum and Plasmodium vivax infections in the Brazilian Amazon region. Clin Vaccine Immunol 2008, 15:650-658

19. Ladislau JLBLMTP: Avaliação do plano de acões de controle da malária na região da Amazonia Legal, Brasil, no contexto da descentralização. Epidemol Serviços Saúde 2006:9-20.

20. Caicedo O, Ramirez O, Mourao MP, Ziadec J, Perez P, Santos JB, Quinones F, Alecrim MG, Arevalo-Herrera M, Lacerda MV, Herrera S: Comparative hematologic analysis of uncomplicated malaria in uniquely different regions of unstable transmission in Brazil and Colombia. Am J Trop Med Hyg 2009, 80:146-151.

21. Costa APBC, Silva S, Cruz MFF, Daniel-Ribeiro CT, Brasil P: Retardo no diagnóstico clínico da malaria na região extra-Amazônica, área endêmica de Dengue: Relato de caso. Rev Soc Bras Med Trop 2009, 42:191

22. Bressan CCA, Brasil P: Infecção fulminante por Plasmodium falciparum em missionária proveniente do Continente Africano: Relato de Caso. Rev Soc Bras Med Trop 2009, 42:119.

23. Vitor-Silva S, Reyes-Lecca RC, Pinheiro TR, Lacerda MV: Malaria is associated with poor school performance in an endemic area of the Brazilian Amazon. Malar J 2009, 8:230

24. Hemmer CJ, Holst FG, Kern P, Chiwakata CB, Dietrich M, Reisinger EC: Stronger host response per parasitized erythrocyte in Plasmodium vivax or ovale than in Plasmodium falciparum malaria. Trop Med Int Health 2006, 11:817-823

25. Cabral PHOAS, Alecrim WD, Alecrim MGC, Lacerda MVG: Malaria and sickle cell anemia: report of complications and clinical management of three patients in a highly endemic area for Plasmodium vivax malaria in the Brazilian Amazon. Case Rep Clin Pract Rev 2006, 7:220-223.

26. Lacerda MV: Clinical manifestations and pathogenesis of the trombocytopenia in malaria Brasilia: Universidade de Brasilia; 2007.

27. Genton B, D'Acremont V, Rare L, Baea K, Reeder JC, Alpers MP, Muller I: Plasmodium vivax and mixed infections are associated with severe malaria in children: a prospective cohort study from Papua New Guinea. PLoS Med 2008, 5:e127.

28. Rodriguez-Morales AJ, Ferrer MV, Barrera MA, Pacheco M, Daza V, FrancoParedes C: Imported cases of malaria admitted to two hospitals of Margarita Island, Venezuela, 1998-2005. Travel Med Infect Dis 2009, 7:44-48.

29. Indicadores e dados basicos - Brasil [http://www2.datasus.gov.br/ DATASUS/index.php]

30. Kochar DK, Saxena V, Singh N, Kochar SK, Kumar SV, Das A: Plasmodium vivax malaria. Emerg Infect Dis 2005, 11:132-134.

31. Kochar DK, Sirohi P, Kochar SK, Budania MP, Lakhotia JP: Dynamics of malaria in Bikaner, Rajasthan, India (1975-2006). J Vector Borne Dis 2007, 44(4):281-284.

32. Santos-Ciminera PD, Roberts DR, Alecrim MG, Costa MR, Quinnan GV Jr: Malaria diagnosis and hospitalization trends, Brazil. Emerg Infect Dis 2007, 13:1597-1600.

33. Alecrim MG: Estudo clinico resistência e polimorfismo parasitario na malária pelo Plasmodium vivax em Manaus (AM) Brasilia: Universidade de Brasilia; 2000

34. Rojanasthien S, Surakamolleart V, Boonpucknavig S, Isarangkura P: Hematological and coagulation studies in malaria. J Med Assoc Thai 1992, 75(Suppl 1):190-194.

35. Lacerda MV, Alexandre MA, Santos PD, Arcanjo AR, Alecrim WD, Alecrim $M G$ : Idiopathic thrombocytopenic purpura due to vivax malaria in the Brazilian Amazon. Acta Trop 2004, 90:187-190.

36. de Lacerda MV, de Oliveira SL, Alecrim MG: Splenic hematoma in a patient with Plasmodium vivax malaria. Rev Soc Bras Med Trop 2007, 40:96-97.

37. Lomar AV, Vidal JE, Lomar FP, Barbas CV, de Matos GJ, Boulos M: Acute respiratory distress syndrome due to vivax malaria: case report and literature review. Braz J Infect Dis 2005, 9:425-430.

38. Costa APCM, Bressan C, Pedro RS, Valls R, Daniel-Ribeiro CT, Brasil P: Malaria de mata Atlântica no estado do Rio de Janeiro. Rev Soc Bras Med Trop 2009, 42:477

39. Alexandre A: Estudo clínico e epidemiológico dos casos graves de malaria vivax em pacientes atendidos na Fundação Medicina Tropical do Amazonas Brasil. Manaus: Universidade do Estado do Amazonas; 2004

40. Song JY, Park CW, Jo YM, Kim JY, Kim JH, Yoon HJ, Kim CH, Lim CS, Cheong HJ, Kim WJ: Two cases of Plasmodium vivax Malaria with the clinical picture resembling toxic shock. Am J Trop Med Hyg 2007, 77:609-611.

41. de Lacerda MV, Zackiewicz C, Alecrim WD, Alecrim MG: The neglected Plasmodium vivax: are researchers from endemic areas really concerned about new treatment options? Rev Soc Bras Med Trop 2007, 40:489-490.

42. Santana MS, de Lacerda MV, Barbosa MG, Alecrim WD, Alecrim MG: Glucose-6-phosphate dehydrogenase deficiency in an endemic area for malaria in Manaus: a cross-sectional survey in the Brazilian Amazon. PLoS One 2009, 4(4):e5259.

43. Santana MS, da Rocha MA, Arcanjo AR, Sardinha JF, Alecrim WD, Alecrim MG: [Association of methemoglobinemia and glucose-6-phosphate dehydrogenase deficiency in malaria patients treated with primaquine](in Portuguese). Rev Soc Bras Med Trop 2007, 40:533-536.

44. Alecrim M, Alecrim W, Macedo V, Korves C, Roberts D, Li J, Sullivan M, Mccutchan T: Descripotion of a possible clonal expansion of Plasmodium vivax in Manaus-Amazonas-Brazil. Rev Soc Bras Med Trop 1999, 32:303-305.

45. Alecrim M, Alecrim W, Macedo V: Plasmodium vivax resistance to chloroquine (R2) and mefloquine (R3) in Brazilian Amazon region. Rev Soc Bras Med Trop 1999, 32:67-68.

46. de Santana Filho FS, Arcanjo AR, Chehuan YM, Costa MR, MartinezEspinosa FE, Vieira JL, Barbosa MG, Alecrim WD, Alecrim MG: Chloroquine-resistant Plasmodium vivax, Brazilian Amazon. Emerg Infect Dis 2007, 13:1125-1126.

47. Bray PG, Deed S, Fox E, Kalkanidis M, Mungthin M, Deady LW, Tilley L: Primaquine synergises the activity of chloroquine against chloroquineresistant $P$. falciparum. Biochem Pharmacol 2005, 70:1158-1166.

48. Curado I, Duarte AM, Lal AA, Oliveira SG, Kloetzel JK: Antibodies anti bloodstream and circumsporozoite antigens (Plasmodium vivax and Plasmodium malariae/P. brasilianum) in areas of very low malaria endemicity in Brazil. Mem Inst Oswaldo Cruz 1997, 92:235-243. 
49. Curado I, Dos Santos Malafronte R, de Castro Duarte AM, Kirchgatter K, Branquinho MS, Bianchi Galati EA: Malaria epidemiology in lowendemicity areas of the Atlantic Forest in the Vale do Ribeira, Sao Paulo, Brazil. Acta Trop 2006, 100:54-62.

50. Azevedo AL: Aspectos da epidemiologia da malária e da biologia do Anopheles (Kerteszia) cruzi Dyar\&Knab em vales montanhosos do sistema da mata Atlântica Rio de Janeiro: Instituto Oswaldo Cruz - Fiocruz; 1997.

51. Deane LM: Simian malaria in Brazil. Mem Inst Oswaldo Cruz 1992, 87(Suppl 3):1-20.

52. Cerutti C, Boulos M, Coutinho AF, Hatab MDLD, Falqueto A, Rezende HR, Duarte AMRC, Collins W, Malafronte RS: Epidemiologic aspects of the malaria transmission cycle in an area of very low incidence in Brazil. Malar J 2007, 6:33

53. Scopel KKG, Fontes CJF, Nunes AC, Horta MF, Braga TA: High prevalence of Plasmodium malariae infections in a Brazilian Amazon endemic area (Apiacas-Mato Grosso State) as detected by polymerase chain reaction. Acta Trop 2004, 90:61-64.

54. Cox-Singh J, Davis TM, Lee KS, Shamsul SS, Matusop A, Ratnam S, Rahman $H A$, Conway DJ, Singh B: Plasmodium knowlesi malaria in humans is widely distributed and potentially life threatening. Clin Infect Dis 2008, 46:165-171

55. Gadelha P: From "forest malaria" to "bromeliad malaria": a case-study of scientific controversy and malaria control. Parassitologia 1994, 36:175-195.

56. Garnham PCBR, Bruce-Chwatt L, Draper CC, Killick-Kendrick R, Sergiev PG, Tiburskaja NA, Shute PG, Maryon M: A strain of Plasmodium vivax characterized by prolonged incubation: morphological and biological characteristics. Bull World Health Organ 1975, 52:21-32

57. Kirchgatter K, Del Portillo HA: Clinical and molecular aspects of severe malaria. An Acad Bras Cienc 2005, 77:455-475.

58. Castilla RE, Sawyer DO: Malaria rates and fate: a socioeconomic study of malaria in Brazil. Soc Sci Med 1993, 37:1137-1145.

59. Prata A, Urdaneta M, Tada MS, McGreevy PB: Infrequency of asymptomatic malaria in an endemic area in Amazonas Brazil. Rev Inst Med Trop Sao Paulo 1998:51-54.

60. Alves FP, Durlacher RR, Menezes MJ, Krieger H, Silva LH, Camargo EP: High prevalence of asymptomatic Plasmodium vivax and Plasmodium falciparum infections in native Amazonian populations. Am J Trop Med Hyg 2002, 66:641-648.

61. Camargo EP, Alves F, Pereira da Silva LH: Symptomless Plasmodium vivax infections in native Amazonians. Lancet 1999, 353:1415-1416.

62. Coura JR, Suarez-Mutis M, Ladeia-Andrade S: A new challenge for malaria control in Brazil: asymptomatic Plasmodium infection--a review. Mem Inst Oswaldo Cruz 2006, 101:229-237.

63. Tran TM, Oliveira-Ferreira J, Moreno A, Santos F, Yazdani SS, Chitnis CE, Altman JD, Meyer EV, Barnwell JW, Galinski MR: Comparison of IgG reactivities to Plasmodium vivax merozoite invasion antigens in a Brazilian Amazon population. Am J Trop Med Hyg 2005, 73:244-255

64. Baird JK: Age-dependent characteristics of protection v. susceptibility to Plasmodium falciparum. Ann Trop Med Parasitol 1998, 92:367-390.

65. Oliveira-Ferreira J, Nakaie CR, Daniel-Ribeiro C: Low frequency of antiPlasmodium falciparum circumsporozoite repeat antibodies and rate of high malaria transmission in endemic areas of Rondonia State in northwestern Brazil. Am J Trop Med Hyg 1992, 46:720-726.

66. Ferreira MU, Camargo LM, de Carvalho ME, Ninomia RT, Garcia LA, dos Santos FR: Prevalence and levels of IgG and IgM antibodies against Plasmodium falciparum and P. vivax in blood donors from Rondonia, Brazilian Amazon. Mem Inst Oswaldo Cruz 1993, 88:263-269.

67. Banic DM, Bossus M, Delplace P, Tartar A, Gras-Masse H, Conseil V, Mazingue C, de Taisne C, Camus D: Immunogenicity and antigenicity of the $\mathrm{N}$-term repeat amino acid sequence of the Plasmodium falciparum P126 antigen. Mem Inst Oswaldo Cruz 1992, 87(Suppl 3):159-162.

68. Banic DM, de Oliveira-Ferreira J, Pratt-Riccio LR, Conseil V, Goncalves D, Fialho RR, Gras-Masse H, Daniel-Ribeiro CT, Camus D: Immune response and lack of immune response to Plasmodium falciparum P126 antigen and its amino-terminal repeat in malaria-infected humans. Am J Trop Med Hyg 1998, 58:768-774

69. Jacobson KC, Thurman J, Schmidt CM, Rickel E, Oliviera de Ferreira J, Ferreira-da-Cruz MF, Daniel-Ribeiro CT, Howard RF: A study of antibody and $T$ cell recognition of rhoptry-associated protein-1 (RAP-1) and RAP-2 recombinant proteins and peptides of Plasmodium falciparum in migrants and residents of the state of Rondonia, Brazil. Am J Trop Med Hyg 1998, 59:208-216.

70. Pratt-Riccio LR, Lima-Junior JC, Carvalho LJ, Theisen M, Espindola-Mendes EC, Santos F, Oliveira-Ferreira J, Goldberg AC, Daniel-Ribeiro CT, Banic DM: Antibody response profiles induced by Plasmodium falciparum glutamate-rich protein in naturally exposed individuals from a Brazilian area endemic for malaria. Am J Trop Med Hyg 2005, 73:1096-1103

71. Scopel KK, Fontes CJ, Ferreira MU, Braga EM: Plasmodium falciparum: IgG subclass antibody response to merozoite surface protein- 1 among Amazonian gold miners, in relation to infection status and disease expression. Exp Parasitol 2005, 109:124-134.

72. Taylor RR, Allen SJ, Greenwood BM, Riley EM: IgG3 antibodies to Plasmodium falciparum merozoite surface protein 2 (MSP2): increasing prevalence with age and association with clinical immunity to malaria. Am J Trop Med Hyg 1998, 58:406-413.

73. Braga EM, Barros RM, Reis TA, Fontes CJ, Morais CG, Martins MS, Krettli AU: Association of the $\mathrm{IgG}$ response to Plasmodium falciparum merozoite protein (C-terminal $19 \mathrm{kD}$ ) with clinical immunity to malaria in the Brazilian Amazon region. Am J Trop Med Hyg 2002, 66:461-466.

74. Braga EM, Carvalho LH, Fontes CJ, Krettli AU: Low cellular response in vitro among subjects with long-term exposure to malaria transmission in Brazilian endemic areas. Am J Trop Med Hyg 2002, 66:299-303.

75. Ferreira MU, Kimura EA, Katzin AM, Santos-Neto LL, Ferrari JO, Villalobos JM, de Carvalho ME: The IgG-subclass distribution of naturally acquired antibodies to Plasmodium falciparum, in relation to malaria exposure and severity. Ann Trop Med Parasitol 1998, 92:245-256.

76. Sabchareon A, Burnouf T, Ouattara D, Attanath P, Bouharoun-Tayoun H, Chantavanich P, Foucault C, Chongsuphajaisiddhi T, Druilhe P: Parasitologic and clinical human response to immunoglobulin administration in falciparum malaria. Am J Trop Med Hyg 1991, 45:297-308

77. de Arruda ME, Aragaki C, Gagliardi F, Haile RW: A seroprevalence and descriptive epidemiological study of malaria among Indian tribes of the Amazon basin of Brazil. Ann Trop Med Parasitol 1996, 90:135-143.

78. Qari SH, Shi YP, Goldman IF, Udhayakumar V, Alpers MP, Collins WE, Lal AA: Identification of Plasmodium vivax-like human malaria parasite. Lancet 1993, 341:780-783.

79. Rosenberg R, Wirtz RA, Lanar DE, Sattabongkot J, Hall T, Waters AP, Prasittisuk C: Circumsporozoite protein heterogeneity in the human malaria parasite Plasmodium vivax. Science 1989, 245:973-976.

80. Arruda ME, Souza RC, Veiga EM, Ferreira F, Zimmerman RH: Prevalence of Plasmodium vivax variants VK247 and P. vivax-like human malaria: a retrosprctive study in indigenous Indian populations of the Amazon region Brazil. Trans R Soc Trop Med Hyg 1998, 92:628.

81. Kremsner PG, Neifer S, Bienzle U, Rocha RM, Clavijo P, Nissenzweig RS, Cochrane AH: Prevalence and level of antibodies to the circumsporozoite proteins of human malaria parasites, including distinct areas in the State of Acre Brazil. Trans R Soc Trop Med Hyg 1992, 86:23-27.

82. Marelli MT, Branquinho MS, Hoffman EHE, Benevento CM, Natal D, TaipeLagos CB, Kloetzel JK: ELISA with P. vivax-like/P. simiovale CS repeats in human sera and anopheline from the State of Acre, Brazil. Mem Inst Oswaldo Cruz 1997, 92:268.

83. Morais CG, Soares IS, Carvalho LH, Fontes CJ, Krettli AU, Braga EM: Antibodies to Plasmodium vivax apical membrane antigen 1: persistence and correlation with malaria transmission intensity. Am J Trop Med Hyg 2006, 75:582-587.

84. Levitus G, Mertens F, Speranca MA, Camargo LM, Ferreira MU, del Portillo $H A$ : Characterization of naturally acquired human IgG responses against the $\mathrm{N}$-terminal region of the merozoite surface protein 1 of Plasmodium vivax. Am J Trop Med Hyg 1994, 51:68-76.

85. Ladeia-Andrade S, Ferreira MU, Scopel KK, Braga EM, Bastos Mda S, Wunderlich G, Coura JR: Naturally acquired antibodies to merozoite surface protein (MSP)-1(19) and cumulative exposure to Plasmodium falciparum and Plasmodium vivax in remote populations of the Amazon Basin of Brazil. Mem Inst Oswaldo Cruz 2007, 102:943-951.

86. Mertens F, Levitus G, Camargo LM, Ferreira MU, Dutra AP, Del Portillo HA: Longitudinal study of naturally acquired humoral immune responses against the merozoite surface protein 1 of Plasmodium vivax in patients from Rondonia, Brazil. Am J Trop Med Hyg 1993, 49:383-392. 
87. Morais CG, Soares IS, Carvalho LH, Fontes CJ, Krettli AU, Braga EM: IgG isotype to C-terminal $19 \mathrm{kDa}$ of Plasmodium vivax merozoite surface protein 1 among subjects with different levels of exposure to malaria in Brazil. Parasitol Res 2005, 95:420-426.

88. Curado I, Duarte AMRC, Lal AA, Oliveira SG, Kloetzel JK: Antibodies anti bloodstream and circumsporozoite antigens (Plasmodium vivax and Plasmodium malariae/P. brasilianum) in areas of very low malaria endemicity in Brazil. Mem Inst Oswaldo Cruz 1997, 92:235-243.

89. Lima-Junior JC, Tran TM, Meyer EV, Singh B, De-Simone SG, Santos F, Daniel-Ribeiro CT, Moreno A, Barnwell JW, Galinski MR, Oliveira-Ferreira J: Naturally acquired humoral and cellular immune responses to Plasmodium vivax merozoite surface protein 9 in Northwestern Amazon individuals. Vaccine 2008, 26:6645-6654.

90. Ceravolo IP, Sanchez BA, Sousa TN, Guerra BM, Soares IS, Braga EM, McHenry AM, Adams JH, Brito CF, Carvalho LH: Naturally acquired inhibitory antibodies to Plasmodium vivax Duffy binding protein are short-lived and allele-specific following a single malaria infection. Clin Exp Immunol 2009, 156:502-510.

91. Soares IS, da Cunha MG, Silva MN, Souza JM, Del Portillo HA, Rodrigues MM: Longevity of naturally acquired antibody responses to the $\mathrm{N}$ - and C-terminal regions of Plasmodium vivax merozoite surface protein 1. Am J Trop Med Hyg 1999, 60:357-363.

92. Nogueira PA, Alves FP, Fernandez-Becerra C, Pein O, Santos NR, Pereira da Silva LH, Camargo EP, del Portillo HA: A reduced risk of infection with Plasmodium vivax and clinical protection against malaria are associated with antibodies against the $\mathrm{N}$ terminus but not the $\mathrm{C}$ terminus of merozoite surface protein 1. Infect Immun 2006, 74:2726-2733.

93. Daniel-Ribeiro CT, Portillo Del H, Zalis MG, Póvoa MM, Tauil PL: Repertoire of the groups conducting malaria research in Brazil 2007:116.

94. Fundação UIA: A região Amazonica. [http:// ambientes.ambientebrasil.com.br/natural/biomas/floresta amazonica localizacao.html ].

95. [http://www.ioc.fiocruz.br/laverandeane/]

96. [https://sistemas.usp.br/fenixweb/fexDisciplina?sgldis=MIP5714].

97. [http://www.inpa.gov.br].

doi: $10.1186 / 1475-2875-9-115$

Cite this article as: Oliveira-Ferreira et al., Malaria in Brazil: an overview Malaria Journal 2010, 9:115

\section{Submit your next manuscript to BioMed Central} and take full advantage of:

- Convenient online submission

- Thorough peer review

- No space constraints or color figure charges

- Immediate publication on acceptance

- Inclusion in PubMed, CAS, Scopus and Google Scholar

- Research which is freely available for redistribution

Submit your manuscript at www.biomedcentral.com/submit
C BioMed Central 